\title{
Sistema Verde Urbano de Loja como base estructurante de la ciudad
}

\author{
Loja Urban Green System as the structuring \\ base of the city
}

\author{
Resumen
}

Autores:

Galina Segarra-Morales* gmsegarra2@utpl.edu.ec

Mercedes Torres-Gutiérrez* mctorres27@utpl.edu.ec

Claudia González Roldán* csgonzalez@utpl.edu.ec

*Universidad Técnica Particular de Loja

Ecuador

Recibido: 15/Mar/2021 Aceptado: 12/Jun/2021
$\mathbf{L}$ a infraestructura verde se constituye en una nueva forma de planificar y gestionar el territorio como una red de espacios naturales y seminaturales que ofrecen varios servicios ecosistémicos, tomando especial importancia en el entorno urbano por su aporte a la mejora para la calidad de vida, conservación de la biodiversidad y vinculación con el contexto rural. Este trabajo aborda la identificación y estructuración de los elementos del sistema en una ciudad rodeada de un potencial natural a través de la introducción a su significado, la lectura sistémica de sus elementos en el contexto de la hoya de Loja para su análisis y configuración, con visión de orientar su gestión y conformación. Así, el sistema verde urbano de Loja trata de constituirse en el elemento vertebrador de una ciudad sostenible que contribuya a crear un mejor lugar para vivir en relación con la naturaleza.

Palabras clave: infraestructura verde; sistema verde; biodiversidad; ciudad sostenible; Loja.

\section{Abstract:}

Green infrastructure constitutes a new way of planning and managing the territory as a network of natural and semi-natural spaces that offer various ecosystem services; taking special importance in the urban environment for its contribution to the improvement of the quality of life, the conservation of biodiversity and the link with the rural context. This research addresses the identification and structure of the system's elements in a city surrounded by a natural potential, through the introduction to its meaning, the systemic understanding of its elements in the case of the basin of Loja for its analysis and configuration, with a vision of guiding its management and conception. Thus, the urban green system of Loja tries to become the support of a sustainable city that contributes to creating a better place to live in relation to nature.

Keywords: green infrastructure; green system; biodiversity; sustainable city; Loja. 


\section{Introducción}

En el actual siglo urbano, la mayor parte de la población habita en las ciudades y con ello se pone en evidencia la urgente necesidad de retomar la relación del medio construido con la naturaleza para favorecer la condición humana con calidad de vida. Es preciso, entonces, reorientar los objetivos de la planificación urbana y la ordenación del territorio, en donde los recursos naturales condicionan la permanencia de las ciudades.

La presencia de los espacios verdes en la vida urbana permite que los procesos dinámicos se desarrollen en un equilibrio ambiental que se encamina hacia la sostenibilidad y soporte de las demandas de energía, suelo y agua que las ciudades requieren (Vásquez, 2016). En el contexto de la naturaleza y la vida urbana, los espacios verdes están asociados a las propuestas del siglo XX, en donde el Movimiento Moderno les dio cabida como elementos estructuradores de los modelos urbanos y se conceptualizan, según Fadigas (2009), como el conjunto de áreas libres, ordenadas o no, recubiertas de vegetación, que desempeñan funciones de protección del medio ambiente urbano, de integración paisajística, arquitectónica o de recreo. Se incluyen en la definición: parques urbanos públicos y privados, áreas de protección ambiental de cursos de agua, laderas cubiertas de vegetación y áreas agrícolas y forestales residuales dentro de los espacios urbanos o urbanizables que conforman sistemas.

Resulta importante reconocer a los sistemas o infraestructura verde como la oportunidad de recuperar el desarrollo sostenible en la ciudad, dando fuerza al crecimiento socioeconómico, a la protección ambiental, a la recreación, destacando su enfoque hacia la planificación urbana que aplique y considere los elementos existentes como las piezas clave para estructurar el crecimiento de la ciudad a partir de la naturaleza (Valdés y Foulkes, 2016). Admitiendo el potencial de la infraestructura verde para fomentar relaciones entre áreas urbanas y entornos rurales, se parte de la hipótesis de que el configurar un sistema verde urbano (SVU) como aplicación de infraestructura verde posibilita desarrollar una red de elementos naturales y seminaturales que potencien los servicios ecosistémicos, mejoren la calidad de vida ciudadana y se articulen a la planificación sostenible de la ciudad (Sahagún et al., 2020).

\subsection{La Infraestructura verde}

En la evolución de conceptos sobre los espacios verdes y la impostergable necesidad de retomar la relación hombre-naturaleza, surge el concepto de infraestructura verde (IV), definida como "una red de zonas naturales y seminaturales y de otros elementos ambientales, planificada de forma estratégica, diseñada y gestionada para la prestación de una extensa gama de servicios ecosistémicos" (Comisión Europea, 2013, p. 3).

Entonces, la IV corresponde a la interacción de espacios verdes diversos, que conllevan variedad de funciones y beneficios bajo principios que hacen referencia a: sistema, diversidad, multifuncionalidad y conectividad (Benedict y McMahon, 2006; Hansen y Pauleit, 2014). Estos cuatro principios han sido tomados para el Sistema de Infraestructura Verde propuesto para la ciudad de Santiago por un equipo multidisciplinario de la Universidad de Chile y el Ministerio de Vivienda y Urbanismo; se reseñan en:

- Sistema: la infraestructura es planificada y gestionada como un sistema de espacios verdes funcionales y espacialmente relacionados. Esto implica complementariedad y distribución equitativa.

- Diversidad: los espacios verdes son de origen y características diversas, se incluyen espacios naturales, como riberas de ríos, humedales y bosques, hasta espacios antropizados, como parques y plazas, entre otros.

- Multifuncionalidad: Ia IV es concebida y gestionada para cumplir múltiples funciones y entregar simultáneamente diversos beneficios ambientales, sociales y económicos.

- Conectividad: los espacios verdes se vinculan espacialmente con el objetivo de permitir el movimiento de personas, especies de fauna, viento, agua y materia viva entre los componentes del sistema.

No obstante, uno de los retos para la implementación de la IV es su establecimiento como una nueva e innovadora forma de planificación y no simplemente como "iniciativas verdes" aisladas (Matthews et al., 2015). Es así que se tienen referencias a partir de 1990 aplicadas a varias ciudades, desde pequeños asentamientos a grandes áreas metropolitanas; se destacan las experiencias del Anillo Verde de Vitoria Gasteiz (1990), Red de Pasillos Verdes en Berlín (1994), Red Verde de Hamburgo (1997), entre otros en el contexto europeo; Plan Maestro de Recuperación Humedal Coca Maule (2009), Plan Director de Medellín y Parque Metropolitano del Río Medellín (2011), en América Latina.

En el enfoque de la planificación resalta la experiencia alemana, que incluye dos niveles: de paisaje (vinculada con planes generales) y de estructura verde (vinculada con planes locales), buscando la protección de la naturaleza y la regulación de parques y áreas verdes urbanas respectivamente (Valdés y Foulkes, 2016). Desde del nivel regional al local, ciudades alemanas han establecido un marco espacial mediante una serie de instrumentos de ordenación del territorio que se basan en planes integrales y planes sectoriales, guiados por estrategias y políticas, en su mayoría implementados por planes locales que se ajustan a la visión de la IV (Hu et al., 2020). De igual manera, Vitoria Gasteiz, como ciudad media similar al caso de estudio, inicia el proyecto del Anillo Verde con el fin de dar una solución integral a los problemas de la periferia urbana, a partir de una visión de desarrollo que determina planes territoriales parciales y planes sectoriales que abordan las escalas: regional/ comarcal, municipal/local y urbana/barrial mediante estrategias, entre otras, de conservación del paisaje, ordenación de áreas agrícolas y diseño de parques, 
correspondientemente (Centro de Estudios Ambientales, 2016). Por otro lado, el Plan de Ordenamiento Territorial de Medellín interviene de manera conjunta el territorio urbano y rural, formulando el manejo de las microcuencas que se conectan con los espacios públicos de la ciudad; a partir de ello, se enmarcan planes sectoriales que, acorde a la disponibilidad de inversión municipal, implementan proyectos urbanos integrales $\mathrm{PUI}$ en los territorios específicos (Alcaldía de Medellín, 2021).

Bajo estas consideraciones, se reconoce la necesidad de incluir la IV en la planificación del territorio como estructurante de desarrollo sostenible a diferentes escalas, integrando las determinaciones que fueran requeridas para los instrumentos de gestión (ordenanzas, planes especiales, proyectos integrales...). Al tiempo, dado que las actuaciones urbanas tienden a ser vulnerables a los cambios de los periodos político-administrativos, es preciso plantear la IV desde los planes de ordenamiento territoriales, considerando áreas urbanas y rurales que se enmarcan en una visión a largo plazo. Así, es posible articular planes de uso y gestión de suelo, sectoriales y especiales que se fortalecen con diseños participativos locales, estimulando los procesos de organización social y comunitaria.

\subsection{Conformación de la infraestructura verde}

Fadigas (2009) señala que los espacios verdes que conforman la infraestructura se clasifican según su distribución espacial y la relación con el funcionamiento urbano, lo que lleva a identificar la red principal, que enlaza el centro urbano con la periferia rural a través de un continuo paisaje natural que integra elementos más representativos; y la red secundaria, que agrupa espacios menores en relación directa con el entorno construido de uso residencial y los equipamientos menores en mayor cercanía con la vida urbana cotidiana.

Además, es importante referir al Landscape Institute (2009) sobre los elementos del paisaje con potencial de IV a las diferentes escalas: micro-escala barrio: calles arboladas, plazas y plazoletas barriales, jardines privados, cubiertas verdes, pasos peatonales y caminos; escala ciudad: ríos y llanuras de inundación, parques sectoriales, bosques urbanos, frentes de agua y plazas municipales; y escala región: áreas silvestres protegidas, parques nacionales, bordes o playas, senderos estratégicos de larga distancia, bosques, redes de carreteras, cinturones verdes, entre otros. Las escalas que conforman estos elementos permiten, con mayor impacto, mantener o recuperar procesos ecológicos fundamentales para los territorios y su dimensión social.

\subsection{Enfoque de derechos de la infraestructura verde}

La Constitución de la República del Ecuador (2008) reconoce el derecho al disfrute pleno de la ciudad y de sus espacios públicos (Art. 31), así como el derecho al acceso y participación del espacio público como ámbito de deliberación, cohesión social y promoción de la igualdad en la diversidad (Art. 23). Desde el enfoque de derechos humanos es fundamental entender el rol de los espacios públicos verdes en la ciudad como espacios que permiten reducir las brechas de inequidad social y territorial, especialmente de la población que se encuentra en mayor situación de vulnerabilidad. Los grupos socioeconómicos más desfavorecidos suelen ser aquellos que más se benefician del acceso a las mejoras y el incremento de los espacios verdes urbanos (Allen y Balfour, 2014), ya que permiten reducir sus desigualdades vinculadas a menores ingresos, menor calidad de vivienda, localización y déficit de los bienes y servicios urbanos. Por esta razón, el acceso a los espacios públicos verdes permite generar justicia espacial e inclusión social en las ciudades (Silva et al., 2018), facilitando el intercambio e integración entre ciudadanos sin importar su condición económica o social, y rompiendo las barreras de la segregación y exclusión social (Borja, 2012).

Por otra parte, los espacios verdes contribuyen al derecho a un ambiente sano y saludable en las ciudades, permitiendo mejorar la calidad de vida de la población. Varios estudios han comprobado los beneficios de la naturaleza en la ciudad, mejorando la salud mental y física de los habitantes, ya que ofrecen oportunidades para realizar actividad física, mantener el contacto social y disminuir el estrés o la depresión (Hartig et al., 2014; De Vries, 2010). La Constitución del Ecuador es pionera en reconocer los derechos de la naturaleza (Art.71) y esto implica un cambio de paradigma en la forma de planificar las ciudades, donde la estructura ecológica y la naturaleza sean los elementos estructuradores del espacio urbano y donde, además, al ser la naturaleza un sujeto de derechos, se debe respetar y velar integralmente su existencia, el mantenimiento y la regeneración de sus ciclos vitales, funciones y procesos evolutivos.

La Agenda 2030 de los Objetivos de Desarrollo Sostenible reconoce la importancia de incrementar los espacios públicos verdes en las ciudades como parte de las metas del ODS 11: "De aquí a 2030, proporcionar acceso universal a zonas verdes y espacios públicos seguros, inclusivos y accesibles, en particular para las mujeres y los niños, las personas de edad y las personas con discapacidad" (Naciones Unidas, 2021). La Nueva Agenda Urbana (Hábitat III, 2017) recoge también estas aspiraciones para el desarrollo urbano de los próximos años y plantea varios principios que permiten incorporar el enfoque de derechos humanos en la planificación y el diseño de los espacios públicos como: equitativos, inclusivos, seguros, accesibles, verdes y con acción participativa.

Desde los conceptos y premisas internacionales de desarrollo sostenible, este artículo define a la IV como una red de espacios naturales y seminaturales, multifuncionales, diversos y espacialmente vinculados que aporta servicios ecológicos, económicos y sociales para mantener los recursos naturales y mejorar la calidad de vida de la población; además, plantea la visión multiescalar de un Sistema Verde Urbano como implementación de la IV que articule la planificación desde la visión, planes de ordenamiento, sectoriales y locales con la participación ciudadana en las actuaciones territoriales. 


\section{Metodología}

El presente estudio parte de una alianza estratégica entre el programa de Ciudades Intermedias Sostenibles de la Cooperación Alemana GIZ, el Gobierno Municipal y la Academia, buscando convertir a Loja en una ciudad y comunidad sostenible a partir de la estructuración del sistema verde urbano, propuesta que no solo responda de forma consistente con los fundamentos teóricos, sino que además sea coherente y pertinente con las particularidades del territorio.

Considerando los recursos teóricos ya expuestos, y fundamentándonos en el tema del paisaje propuesto por Vásquez (2016) con base en EEA (2011) y Landscape Institute (2009), que proponen identificar los elementos del paisaje de escala regional y de ciudad con potencial de infraestructura verde, sumado al tema de los elementos de la imagen urbana de Kevin Lynch, se plantea una metodología propia que tiene como fin analizar y definir los elementos: núcleos y conectores, su clasificación y escala para conformar el SVU de Loja, no solo analizando esta escala sino el contexto verde desde una mirada multiescalar como contenedora de la ciudad. Parte importante de la metodología aplicada constituye el trabajo colaborativo entre las tres instituciones, además de la implementación de varios talleres con actores locales y expertos en la temática, procedentes de grupos profesionales y de entes públicos; por su parte, la información cartográfica de base ha sido proporcionada por el municipio de la localidad de los años 2010-2014 verificada en campo, uso de ortofotos de satélite año 2017 de uso libre e información generada por las autoras.

De esta forma se trazan dos escalas de análisis: territoria y urbana; así como tres tipos de elementos a considerar: los estructurantes, condicionantes y de oportunidad. Los primeros son de preeminencia para la conformación del SV, dado por su alto grado de naturalidad o por los beneficios sociales relacionados a la recreación y el ocio; los elementos condicionantes dados por elementos abióticos que determinarán como se entretejerá espacialmente el SV de acuerdo a su presencia y distribución en el territorio, y finalmente los elementos de oportunidad, que son aquellos espacios, verdes o no, que representan un potencial para conformar el SV por sus características físico naturales o sociales en beneficio de la comunidad.

Para la escala territorial se han definido, por una parte, los elementos estructurantes, dados por un alto grado de naturalidad, ubicados en el periurbano y rural, siendo las variables a mapear hidrografía, áreas naturales protegidas, tanto las registradas en el Sistema Nacional de Áreas Protegidas como las declaradas por el gobierno local para su conservación, y la geomorfología. Por otra parte se tienen los elementos de oportunidad y condicionantes, dados por suelos en riesgo por movimientos en masa e inundaciones, suelos por su clasificación agrológica aptos para la producción y parques, y finalmente la red de carreteras y senderos.

A escala urbana, siguiendo la misma lógica, se estudian los elementos estructurantes dados por el sistema hídrico que atraviesa la ciudad, el relieve, espacios naturales y seminaturales y espacios públicos artificiales. Como elementos de oportunidad se plantea analizar el suelo con vocación agrícola dentro de las áreas vacantes de la ciudad, suelo que presenta riesgos a deslizamientos en masa e inundaciones, espacios naturales, seminaturales o vacíos urbanos, sean públicos o privados, y elementos para la legibilidad de la ciudad: nodos, hitos, bordes y distritos. Como elementos condicionantes se presenta la mancha urbana dentro del contexto propio de la ciudad y el sistema vial. Todas estas escalas y elementos se interrelacionan espacialmente a través del uso de sistemas de información geográfica; asimismo, se integran con la biodiversidad, que parte desde múltiples inventarios de flora y fauna sobre el territorio de estudio y el trabajo de campo, con el fin de validar y levantar información de forma espacial (Figura 1).

Finalmente, para definir la propuesta del SVU Territorial, se jerarquizan e incorporan de forma espacial

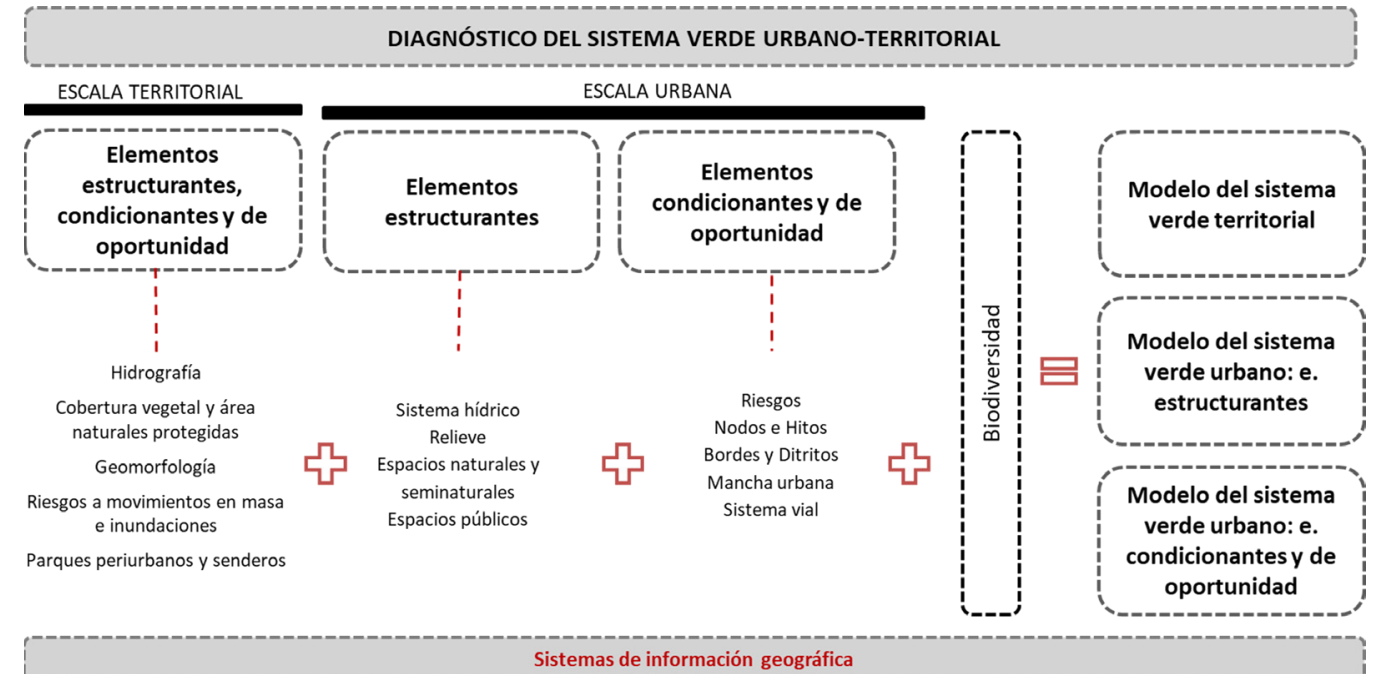

Figura 1: Esquema del proceso metodológico de diagnóstico del SVU Loja

Fuente: Elaboración propia 
(cuantitativa y cualitativa) los núcleos (naturales y artificiales) y conectores naturales, mientras que para los conectores artificiales dados por las vías se utiliza la metodología de sintaxis espacial, que permite identificar las redes óptimas de integración y de conectividad, todo esto vinculado al objetivo de precautelar la biodiversidad. Su organización final se realiza mediante herramientas de sistemas de información geográfica, empleando el análisis sistémico de las relaciones espaciales entre los diferentes elementos, bajo el planteamiento de la visión y estrategias concernientes a la planificación de la ciudad, la conectividad ecosistémica y el derecho a la ciudad, obteniendo finalmente tres escalas de sistema verde a gestionar, la natural y la interfaz que surge de análisis territorial de las áreas rurales y del periurbano, y la urbana, que obedece al ámbito de la ciudad (Figura 2).

\section{Diagnóstico del SVU}

La ciudad de Loja se encuentra ubicada al sur del Ecuador. Cuenta con una población de 170.820 habitantes (INEC, 2010) en una extensión de 5732 hectáreas. Su tipología es propia de las ciudades andinas, asentada en un valle rodeado por brazos de cordillera que derivan de la cordillera Central de los Andes, en su zona más baja, donde no supera los 3.800 m.s.n.m., siendo estos sectores, los denominados periurbano y rural, los que se caracterizan por la presencia de espacios de un alto potencial biofísico propios para re-pensar el desarrollo sostenible de la urbe. En este contexto se requiere identificar los elementos potenciales para estructurar el SVU (Figura 3).

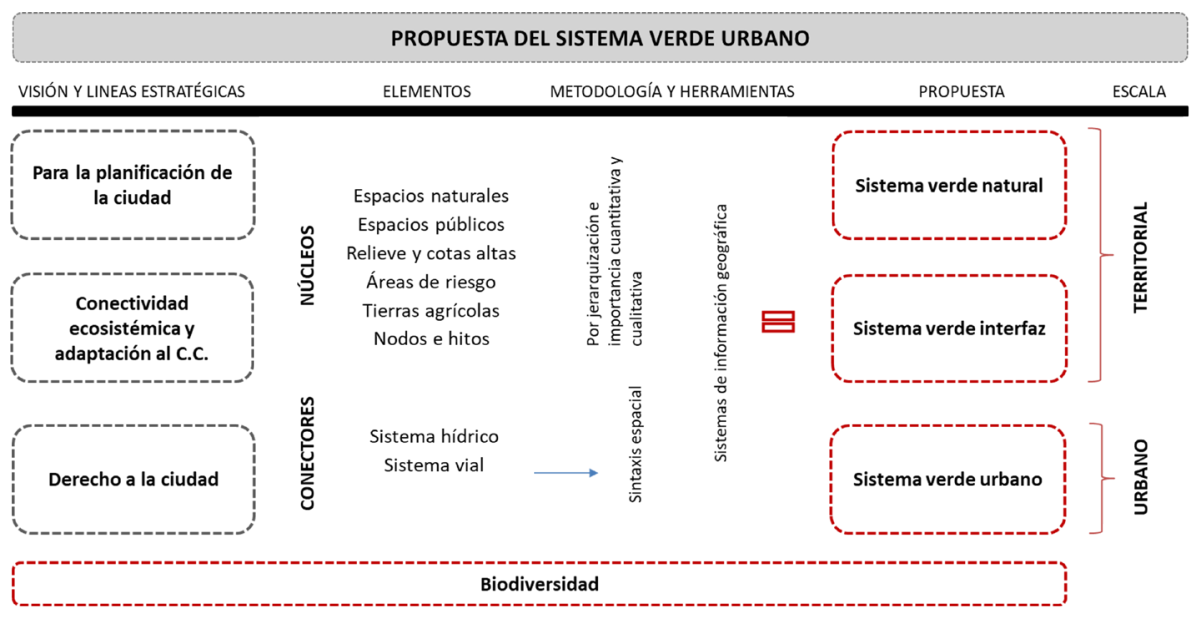

Figura 2: Esquema del proceso metodológico de propuesta del SVU Loja Fuente: Elaboración propia

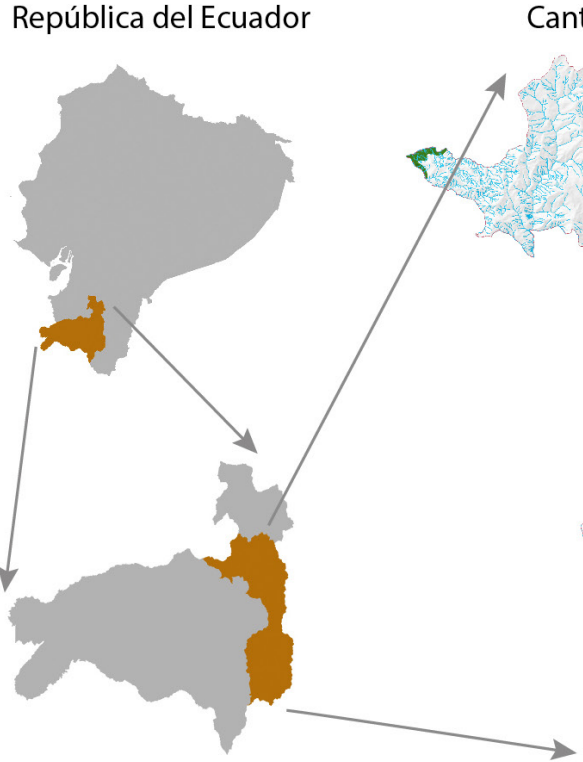

Provincia de Loja
Cantón Loja

Hoya de Loja y perímetro urbano

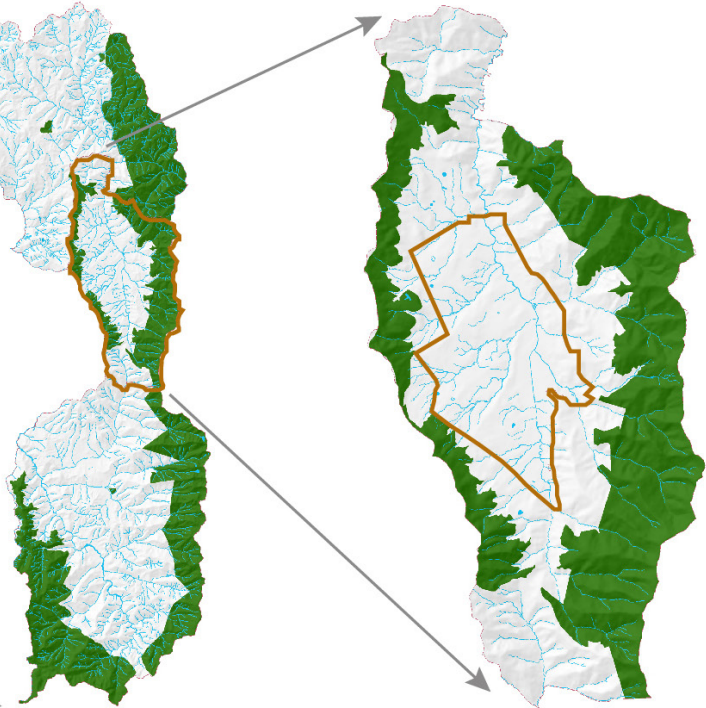

Áreas protegidas e hidrografía

Figura 3: Esquemas de ubicación del caso de estudio, áreas protegidas e hidrografía Fuente: Elaboración propia 
En la escala territorial, siguiendo la metodología planteada, se tiene el mapeo de los elementos estructurantes y de oportunidad. Se encuentra como primer elemento a las áreas protegidas y bosques protectores presentes notoriamente tanto en superficie como en calidad, ubicados hacia los extremos oriental y occidental; hacia el oriente, el estado de conservación es bueno al formar parte del Parque Nacional Podocarpus, mientras que hacia el occidente se presenta deficiente, principalmente por la expansión no planificada de la ciudad. De estos bosques surge todo un sistema hídrico que divide la hoya de Loja en dos cuencas hidrográficas: la Santiago y la Catamayo-Chira. A esto se suman los elementos naturales de geomorfología y cobertura vegetal. Del primero, se destacan los relieves montañosos y colinados que le dan carácter andino a la ciudad, y a la vez modelan el clima del asentamiento que ocupa el eje principal de la cuenca. Con respecto al segundo, presenta principalmente usos de conservación y producción, conservación y protección hacia la parte rural y de producción y sin uso definido conforme se acercan a la ciudad. Hasta aquí ya se puede observar el potencial contundente de estos elementos naturales a escala territorial.

En cuanto a los elementos de oportunidad y condicionantes, por un lado, se tiene el suelo con amenaza a movimientos en masa, que al no ser urbanizable es suelo con oportunidad para generar nuevas áreas dirigidas a la conservación de ecosistemas. Por su parte, los cerros, elevaciones, miradores hacia la ciudad, y los senderos que permiten su accesibilidad, también han sido identificados por su valor cultural, tales como: el Tiro, el Zañe, nudo de Cajanuma, el Uritusinga y en la cordillera del Villonaco, la presencia de los cerros el Ducal y el Villonaco (2.946 m.s.n.m.); finalmente, se mapeó la presencia de un solo parque en el área periurbana, siendo el Carigán de reciente creación (Figura 4).

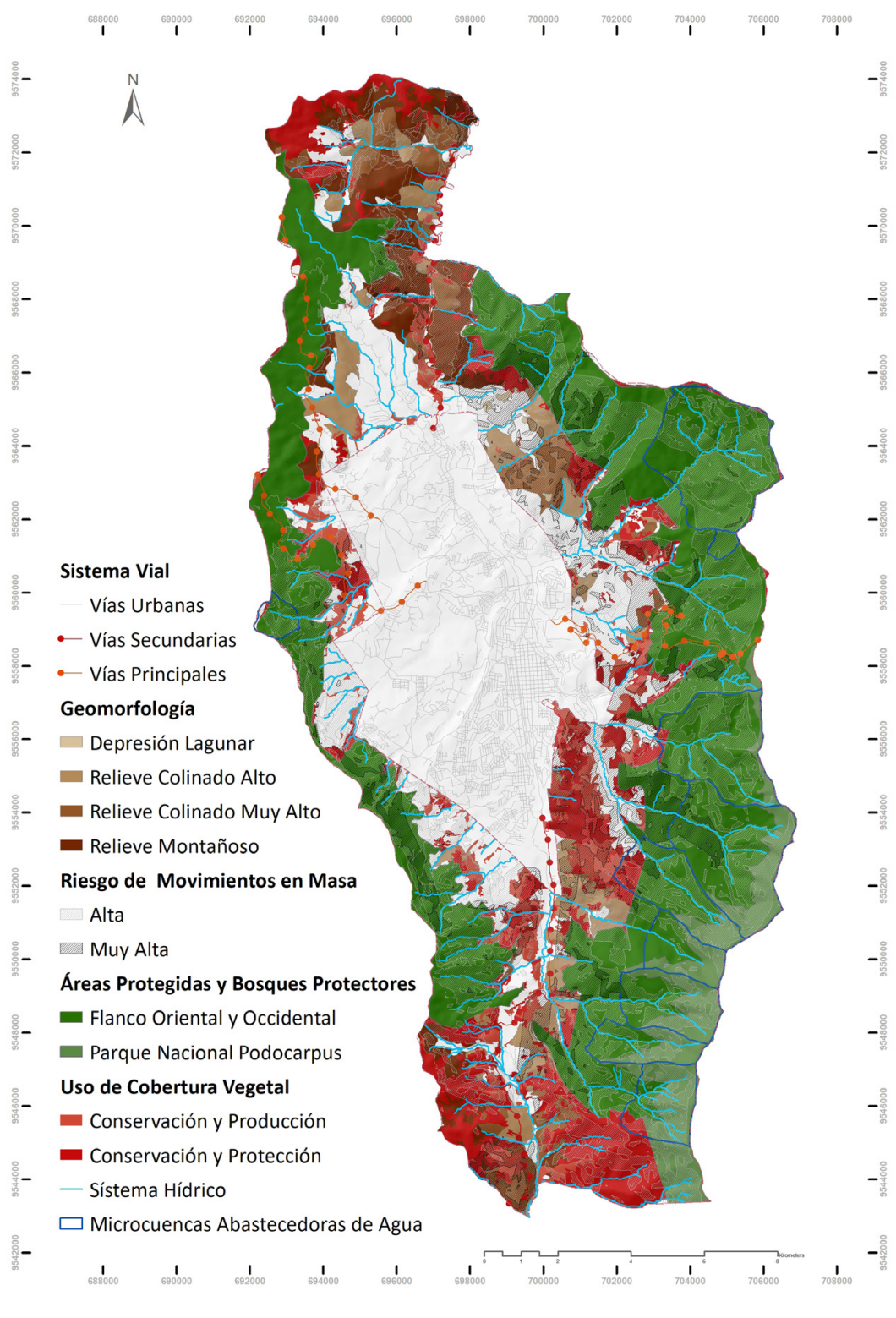

Figura 4: Modelo actual del SVU territorial

Fuente: Elaboración propia a partir de Municipio de Loja, UTPL y GIZ (2020a) 
En la escala urbana se hace referencia al territorio que comprende la superficie dentro del perímetro urbano, una ciudad de morfología alargada $(20 \mathrm{~km} \times 4 \mathrm{~km}$ aproximadamente). En este tejido se han analizado los elementos estructuradores dados por los ríos Malacatos, Zamora y Jipiro, 41 quebradas y lagunas, como sustento en la relación entre naturaleza y lo construido. Si bien por un lado se encuentran en un estado medio a bueno en los sectores más alejados de la urbe, en buena medida se presentan afectados por la contaminación generada por las aguas residuales que se depositan directamente a los cauces de ríos y quebradas, y por alteraciones de los cursos naturales generados por embaulados y pérdida de áreas de protección que han sucumbido ante la urbanización, en donde la densidad poblacional es mayor.

En cuanto a superficie, los espacios públicos de escala urbana son dominantes con relación a los parques barriales y verde comunal, cuya dispersión es mayor hacia los límites de la ciudad, poniendo en evidencia la débil planificación integral en las áreas de expansión ubicadas hacia la periferia de Loja. Al tiempo, los primeros tienen como potencial la proximidad a ríos y quebradas, que significan el continuum natural para el soporte de la biodiversidad y el clima; por el contrario, los espacios púbicos de barrio y en las periferias de la ciudad son escasos y dispersos, pudiéndose asemejar a parches verdes. Es importante además señalar que, al contar con alto porcentaje de suelo urbano vacante, este suelo en el borde occidental (parroquia Carigán), presenta uso de suelo con potencial para la producción agrícola, que de acuerdo a los elementos de paisaje a escala urbana pueden integrase al sistema.

Por otra parte, los elementos condicionantes agrupan áreas de la ciudad que influyen en la conformación de SVU; se refieren a aquellos que, por un lado, componen el tejido de la ciudad, y por otro los que presentan características físicas y geomorfológicas que subordinan la ocupación de suelo para fines constructivos, siendo potencial para integrar el sistema. La mancha urbana denota la mayor área de la ciudad que condiciona la estructuración del SVU. El crecimiento longitudinal a partir del centro histórico marca la aparición de las principales vías en sentido norte-sur, cuyas dimensiones admiten la presencia de parterres verdes parcialmente fragmentados y otros sin uso; a esto se suma el alto grado de consolidación de la ciudad hacia el centro que limita las conexiones transversales, imposibilitando el vínculo y continuidad espacial de la biodiversidad de la cordillera oriental con el borde occidental. No obstante, la dispersión de lo construido hacia la periferia de la ciudad constituye la oportunidad de fortalecer el SVU y organizar el crecimiento de la misma.

Los hitos, que corresponden a los lugares en el interior de la ciudad, cuyas características de ubicación y de identidad cultural resultan estratégicas para el sistema, se emplazan principalmente en zonas altas en varios puntos de la urbe. Los nodos, como espacios públicos o privados, que debido a su uso y cobertura vegetal se pueden convertir en áreas de oportunidad, refieren a cementerios, estadio, jardín botánico, bancos de germoplasma, entre los más representativos. El análisis de las zonas de riesgo a deslizamiento evidencia el potencial de conformación del sistema a partir de la geomorfología de la ciudad, resaltando esencialmente áreas de oportunidad que, en la actualidad, presentan características de borde hacia el occidente y áreas cuyas dimensiones denotan pautas para articular el sistema a nivel territorial hacia el oriente. Los bordes, identificados con pendientes abruptas, actúan como rupturas para el tejido urbano con potenciales vínculos de las áreas protegidas y bosques protectores de la hoya de Loja hacia el centro de la ciudad a través de filamentos transversales que cruzan la periferia (Figura 5).

Con respecto a la biodiversidad, a escala territorial se encuentra un fuerte desequilibrio, ya que la mayoría de servicios ecosistémicos de regulación están conservados en la zona oriental de la Hoya, existiendo al menos 118 especies de aves. De estas, al menos 12 especies se consideran endémicas de alguna de las regiones de endemismo del sur de Ecuador, dejando en evidencia el mal estado de conservación de la zona occidental (Municipio de Loja, UTPL y GIZ, 2020a). Las amenazas más frecuentes son los incendios forestales/agrícolas, extractivismo y aprovechamiento ilegal de productos no maderables; apertura de carreteras, escasa conciencia ambiental, ganadería y agricultura desordenada; ampliación de frontera agropecuaria hacia el interior de los bosques, contaminación, fragmentación de hábitats, plantación de especies exóticas, entre las principales (CINFA y Herbario Loja, 2006). De igual forma, el periurbano guarda una dicotomía, dado que los servicios de abastecimiento se emplazan principalmente en la zona occidental, presentando amplios territorios desprovistos de vegetación, lo cual limita los servicios de regulación. A esta escala las especies de aves se reducen a 44 especies, y en cuanto a herpetofauna a 12 especies. Finalmente, a escala urbana, baja la calidad ambiental y los servicios de regulación, encontrando biodiversidad principalmente para servicios culturales; las especies de aves se reducen a 24, y a 8 especies en cuanto a herpetofauna (Municipio de Loja, UTPL y GIZ, 2020a).

\section{Propuesta del SVU}

La Agencia Europea de Medioambiente plantea que, en el proceso de desarrollo de una estrategia de infraestructura verde, deben incluirse los entornos colindantes para así conseguir la conectividad tanto del medio territorial, periurbano y urbano, potenciando así los beneficios que sobrepasan la escala local (Davies et al, 2015). Alineado a esta condición, el SVU de la ciudad de Loja se circunscribe en su hoya como un entorno territorial/rural y de transición urbano-rural, con oportunidades de usos de suelo con vocación para protección y conectividad ecosistémica que enlacen el entorno natural -espacio verde y azul- con la ciudad-espacio gris. Así, el planteamiento se vincula con los resultados del diagnóstico para reinterpretar sus elementos condicionantes, determinantes y de oportunidad con sus potenciales ecosistémicos y biodiversos a través del planteamiento del SVU en sus tres escalas de conformación (Figura 6) 


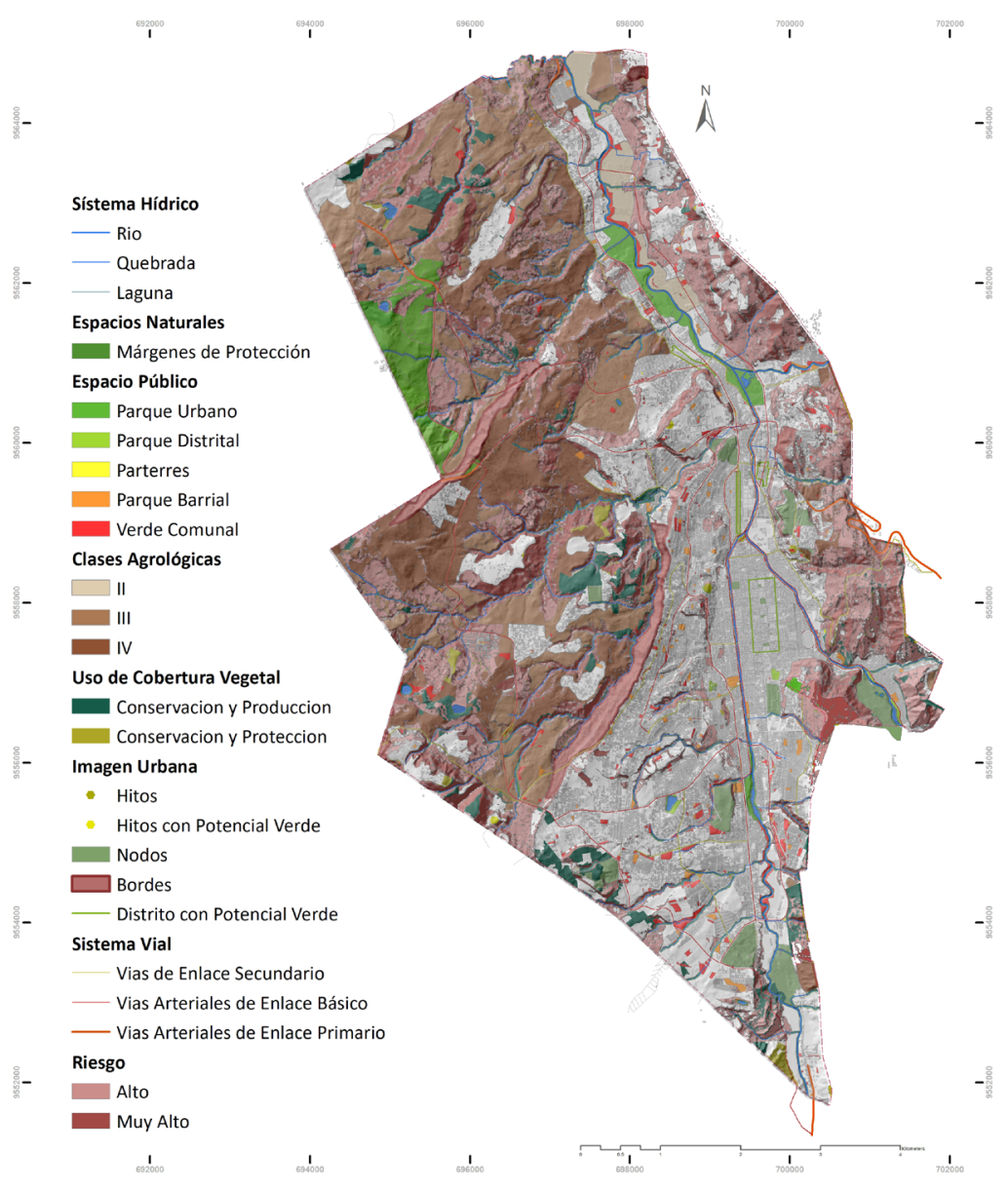

Figura 5: Modelo actual del SVU urbano

Fuente: Elaboración propia a partir de Municipio de Loja, UTPL y GIZ (2020a)

\subsection{Escala territorial: sistema verde natural (SVN)}

El SVN corresponde a una superficie extensa de territorio en estado nativo, con escasa intervención humana y de urbanización. Para este sistema se plantea la conformación de un cinturón verde en el cual se deben reducir al mínimo las actividades antrópicas, con el fin de protegerlas y conservarlas para mantener su biodiversidad. La conformación del SVN tiene las características siguientes:

- La puesta en valor del patrimonio natural identificado principalmente por la presencia de parte del Parque Nacional Podocarpus -PNP-, los tres bosques protectores (Corazón de Oro, Hoya de Loja Oriental y Hoya de Loja Occidental), páramos de tipo arbustivo propios de cantón Loja, coincidentes con el PNP al oriente y con el bosque Hoya de Loja Occidental. Todos estos elementos son gestionados a través de programas de manejo y conservación, especialmente el bosque Hoya de Loja Occidental, que se encuentra en un estado actual de

1 Son áreas invariantes del territorio, ya que han sido ordenadas y delimitadas estratégicamente por sus condiciones ambientales y ecológicas. Estas áreas comprenden el Sistema Nacional de Áreas Protegidas del Ecuador-SNAP. Esta zona comprende espacios ecosistemas frágiles por una incorrecta conservación - El sistema hídrico que atraviesa la hoya longitudinal y transversalmente, correspondiente a tres ríos (Malacatos, Zamora y Jipiro), quebradas y lagunas, con sus márgenes de protección para especies vegetales y bosques nativos. - Las microcuencas abastecedoras de agua para consumo humano, para garantizar el aprovisionamiento de este recurso en el tiempo, correspondiente a las microcuencas de Carmen, San Simón, Pizarros y Jipiro, siendo espacialmente coincidentes con las áreas protegidas (Parque Nacional Podocarpus y Hoya de Loja Oriental).

- La incorporación de nuevas áreas con uso de suelo para conservación y protección, comprendiendo las coberturas vegetales de bosque nativo, vegetación arbustiva, páramos y vegetación herbácea; áreas que ayudarán a conformar el cinturón verde, especialmente en la parte sur de la hoya, y que además permitirán su unión con los bosques oriental y occidental.

- La incorporación de áreas que desde su geomorfología presentan la característica de relieve montañoso y

poco alterados por la acción humana, de gran valor ecológico y ecosistémico.

${ }^{2}$ Dentro del área de influencia de la reserva de biósfera Podocarpus - El Cóndor.

3 Vegetación comprendida sobre los 2800 msnm. que se debe conservar por los servicios ambientales que generan: hídrico, acumulación de carbono, biodiversidad. 

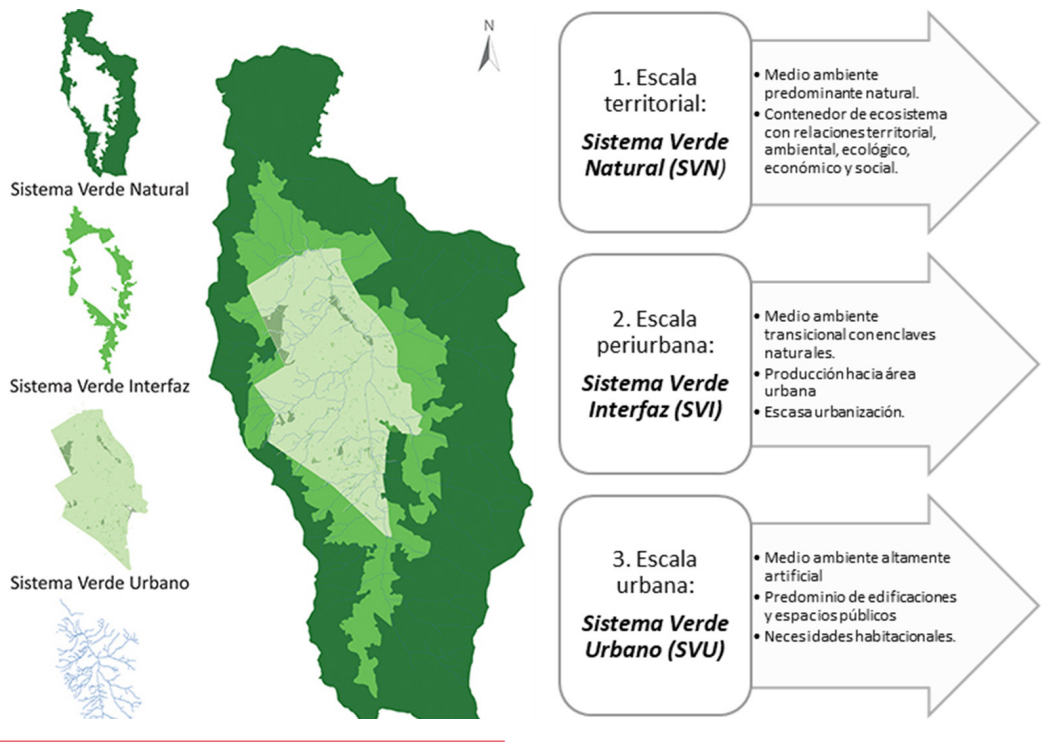

Figura 6: Escalas del SVU de Loja

Fuente: Elaboración propia a partir de Municipio de Loja, UTPL y GIZ (2020a)

colinado muy alto, con pendientes de categoría muy fuerte y fuerte, lo cual ayudará a disminuir la erosión de estos suelos.

- Los servicios ecosistémicos propuestos apuntan al soporte, regulación y provisión de ciclo del agua, la calidad del aire y la regulación climática, entre otros, a través de la conservación y restauración ecológica, la delimitación de áreas intangibles y actuaciones controladas para servicios culturales de recreación de bajo impacto en núcleos y conectores: parque nacional, bosques protectores y nativos, microcuencas y relieves montañosos del SVN (Figura 7).

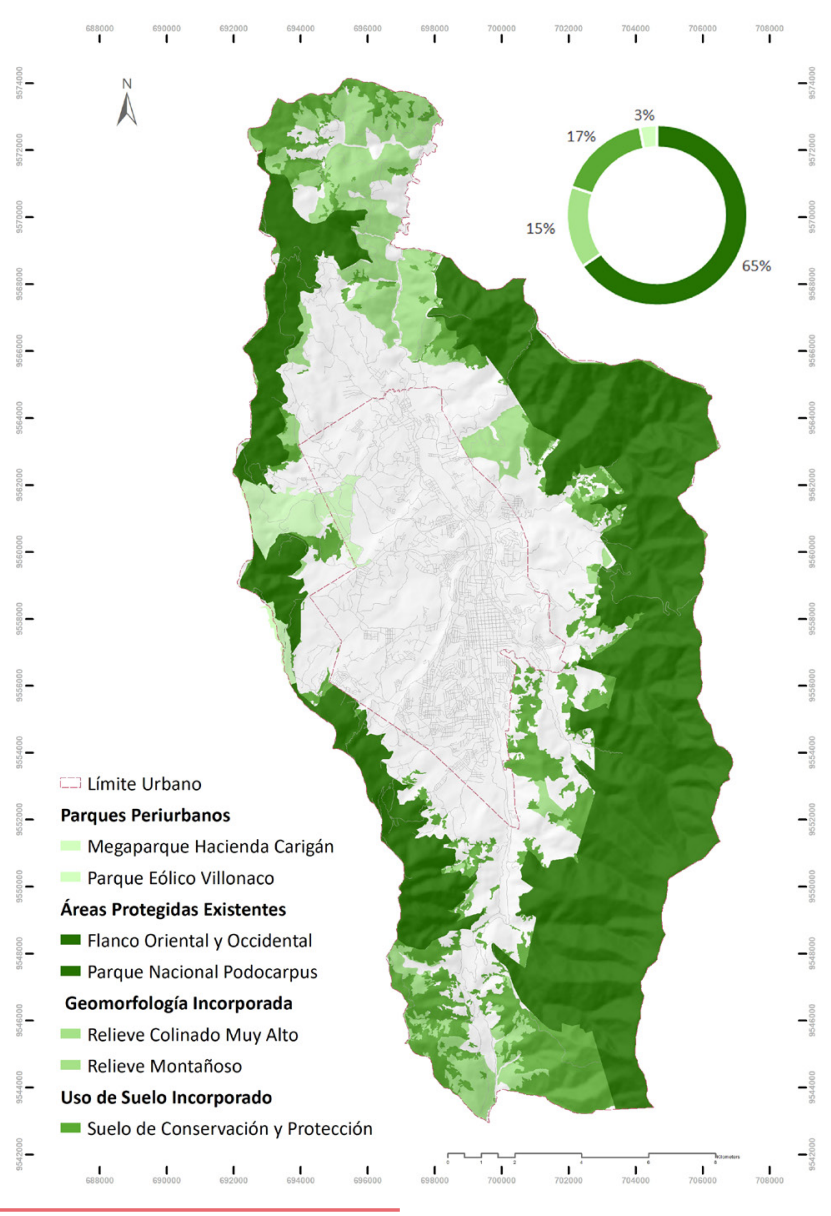

Figura 7: Sistema Verde Natural, escala territorial

Fuente: Elaboración propia a partir de Municipio de Loja, UTPL y GIZ (2020a) 


\subsection{Escala periurbana: sistema verde interfaz (SVI)}

La escala periurbana corresponde al Sistema Verde Interfaz, conformado por zonas de transición entre la ciudad y los espacios más naturales de explotación agroforestal y de conservación. Se trata de zonas de contacto y tensión entre elementos de diferentes ecosistemas -ecotonos- de especial importancia por funcionar como zonas tampón o de amortiguamiento de los impactos urbanos sobre el sistema físico-natural, en donde para el caso de estudio existen áreas de uso pecuario, producción forestal, riesgos a movimientos en masa por sus altas pendientes, biodiversidad que proporciona beneficios desde la naturaleza a la población.

Este ambiente transicional está en un espacio territoria en donde los ríos, quebradas y sus riberas funcionan a diferentes niveles de eficiencia, como componentes transversales del paisaje que pueden facilitar el flujo de energía y la conexión estructural y funcional entre e sistema verde natural y el urbano. De allí la importancia del SVI, cuya conformación tiene un planteamiento con los siguientes elementos y directrices:
- La cobertura vegetal de plantación forestal, que representa 775.15 hectáreas que pueden ser utilizadas tanto para producción como para conservación.

- La conservación del relieve colinado alto, con una superficie de 1282.76 hectáreas, y con pendientes entre 25 y 70\% para disminuir la erosión de estos suelos.

- Se incorpora como un núcleo el suelo con capacidad agrológica II y $\mathrm{II}^{4}$, que tendrá un uso temporal agrícola proponiendo huertos urbanos en la periferia de la urbe; su superficie es de 818 hectáreas, ubicadas principalmente en el norte de la hoya de Loja.

- Se anexan las áreas en riesgo a movimientos en masa de categoría alta y muy alta de los flancos oriental y occidental, toda vez que siendo suelos no aptos para urbanizar, se constituyen en potenciales áreas para introducir usos relacionados con la naturaleza y que conforman el cinturón verde que contiene a la ciudad de un crecimiento excesivamente horizontal en zonas de riesgo, con potencial ambiental o agrícola.

- Los servicios ecosistémicos propuestos para el SVI tienen relación con la regulación de agua mediante la restauración ecológica de nuevas áreas de conservación y protección de cauces de ríos, el control de la expansión urbana y la producción agroecológica en los elementos que lo conforman (Figura 8)

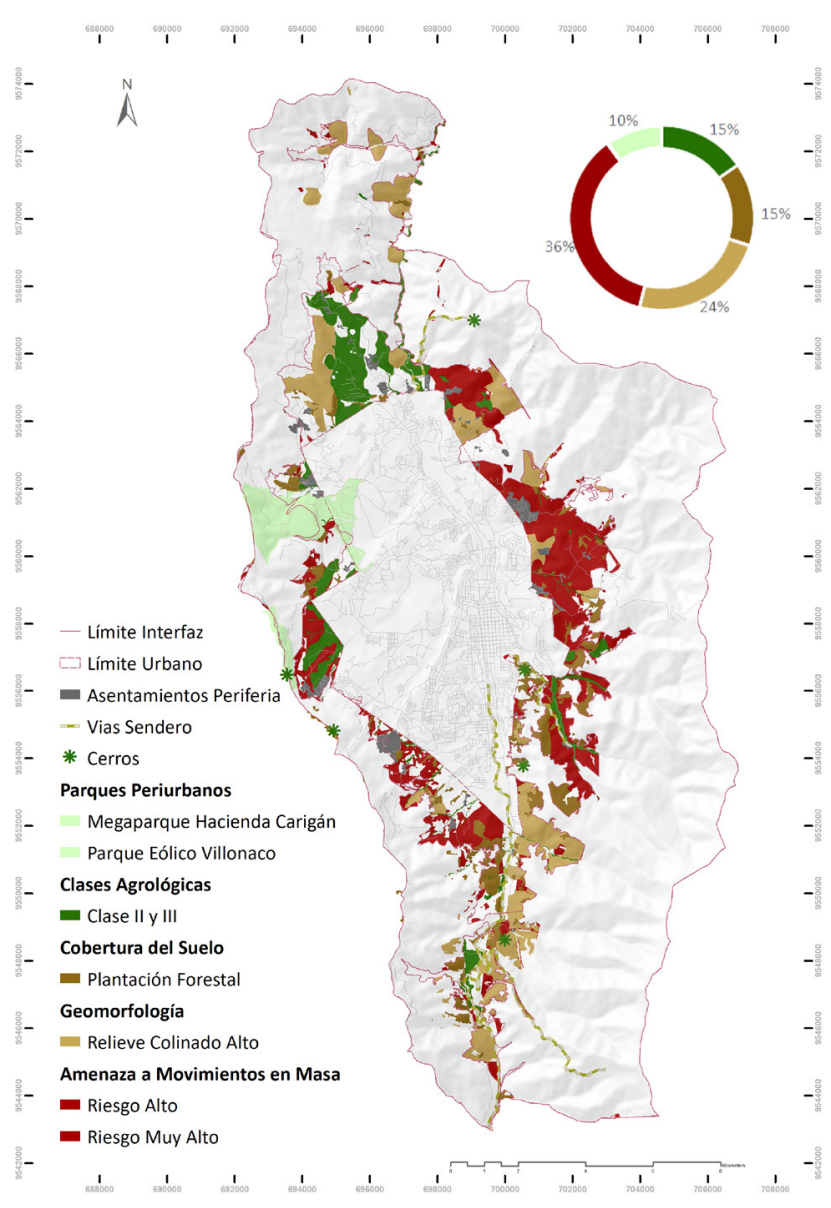

Figura 8: Propuesta Sistema Verde Interfaz, escala periurbana

Fuente: Elaboración propia a partir de Municipio de Loja, UTPL y GIZ (2020a)

4 Capacidad Agrológica II: Suelos con pendientes suaves 3-7\%, de conservación. Capacidad Agrológica III: Suelos ondulados con pendientes entre $12-20 \%$, apropiados para cultivos permanentes, plantaciones forestales y ganadería extensiva. 


\subsection{Escala urbana: sistema verde urbano de Loja (SVU)}

La escala urbana representa el Sistema Verde Urbano de la ciudad de Loja caracterizado en general por sus significativos niveles de intervención humana, tanto en su área urbana como en el entorno periurbano. La formación natural del valle de Loja corresponde a matorral húmedo montano. En la actualidad este se encuentra únicamente alrededor de la hoya, en algunas quebradas y sitios poco accesibles, mientras que en su parte más central el paisaje está dominado por zonas urbanizadas y remanentes de plantaciones de especies exóticas, como pinos y eucaliptos.

En el SVU los elementos analizados como estructurantes, condicionantes y espacios de oportunidad determinan una línea base para organizar espacial y funcionalmente las piezas dentro del límite urbano, que se clasifican en núcleos y conectores. Los núcleos son los espacios con importante grado de naturalidad y condiciones de conservación y restauración ecológica que representan primordiales partes estructuradoras del sistema. Los conectores son elementos que vinculan los núcleos en diversas intensidades según sus potencialidades y aportan la sinergia al sistema propuesto.

\section{a. Núcleos}

Para los elementos núcleos se diseña la clasificación en función de sus áreas, que trae consigo su condición espacial y funcional, para establecerlos en: primarios, secundarios y difusos. Los primarios están comprendidos por los megaparques y los parques urbanos; los núcleos secundarios se integran por parques ancla, bosques urbanos y agricultura urbana, y los difusos son los parques de bolsillo y las áreas permeables privadas (Tabla 1).

\begin{tabular}{|c|c|c|c|}
\hline \multicolumn{4}{|c|}{ NÚCLEOS SVU } \\
\hline Elemento & Tipo & Clasificación & Área \\
\hline Megaparque & Primario & Megaparque & $\begin{array}{c}314.94 \\
\text { ha }\end{array}$ \\
\hline Parque Urbano & Primario & $\begin{array}{l}\text { Parque } \\
\text { Urbano }\end{array}$ & $\begin{array}{c}302.39 \\
\text { ha }\end{array}$ \\
\hline $\begin{array}{c}\text { Parque Sectorial } \\
\text { Parque Barrial }\end{array}$ & Secundarios & Parque Ancla & $\begin{array}{c}142.88 \\
\text { ha }\end{array}$ \\
\hline Área de Riesgo & Secundarios & $\begin{array}{l}\text { Bosque } \\
\text { Urbano }\end{array}$ & $\begin{array}{c}243.54 \\
\text { ha }\end{array}$ \\
\hline $\begin{array}{l}\text { Producción } \\
\text { Agrícola }\end{array}$ & Secundarios & $\begin{array}{l}\text { Agricultura } \\
\text { Urbana }\end{array}$ & $\begin{array}{c}972.31 \\
\text { ha }\end{array}$ \\
\hline Área Residual & Difusos & $\begin{array}{l}\text { Parque de } \\
\text { Bolsillo }\end{array}$ & 2.99 ha \\
\hline Verde Privado & Difusos & $\begin{array}{c}\text { Áreas } \\
\text { Permeables } \\
\text { Privadas }\end{array}$ & 35.11ha \\
\hline
\end{tabular}

Tabla 1: Núcleos del SVU

Fuente: Elaboración propia a partir de Municipio de Loja, UTPL y GIZ (2020a)

\section{b. Conectores}

Los elementos propuestos como conectores conllevan la condición de enlazar los núcleos, canalizando el aprovechamiento de sus posibilidades espaciales como redes naturales y/o construidas para la accesibilidad en las diferentes escalas y los elementos de biodiversidad que poseen en cuanto a flora y fauna; se dividen en naturales y artificiales. Los conectores naturales determinan su condición de ejes originarios con alto potencial de biodiversidad, identificados por una red natural para la gestión del agua mediante la interacción y activación del sistema hídrico y la vinculación con los núcleos existentes y propuestos. Se conforman por: caminos verdes, corredor azul río y corredor azul. Los conectores artificiales corresponden al sistema via urbano y su clasificación, cuyas secciones y elementos determinan la jerarquía espacial de mayor impacto en la vinculación con los tipos de núcleos y su mayor potencial en la recuperación de los ecosistemas urbanos. Se conforman por: corredor verde primario, referido a las vías principales de conexión, corredor verde secundario, que incluye las vías de menor conectividad, y corredor verde complementario, que considera las conexiones que otorgan los senderos y vías menores (Tabla 2).

\begin{tabular}{|c|c|c|c|}
\hline \multicolumn{4}{|c|}{ CONECTORES SVU } \\
\hline Elemento & Tipo & Clasificación & Área \\
\hline \multirow{2}{*}{ Vías } & \multirow{2}{*}{ Artificial } & $\begin{array}{c}\text { Corredor Verde } \\
\text { Primario }\end{array}$ & $\begin{array}{c}111.66 \\
\mathrm{~km}\end{array}$ \\
\cline { 3 - 4 } & & $\begin{array}{c}\text { Corredor Verde } \\
\text { Secundario }\end{array}$ & $\begin{array}{c}116.29 \\
\mathrm{~km}\end{array}$ \\
\cline { 3 - 4 } & & $\begin{array}{c}\text { Corredor Verde } \\
\text { Complementario }\end{array}$ & $6,63 \mathrm{~km}$ \\
\hline Senderos & Natural & Caminos Verdes & $38.11 \mathrm{~km}$ \\
\hline Ríos & Natural & Corredor Azul Río & $20.86 \mathrm{~km}$ \\
\hline Quebradas & Natural & $\begin{array}{c}\text { Corredor Azul } \\
\text { Quebrada }\end{array}$ & $90.51 \mathrm{~km}$ \\
\hline
\end{tabular}

Tabla 2: Conectores del SVU propuesto

Fuente: Elaboración propia a partir de Municipio de Loja, UTPL y GIZ (2020a)

EISVU como propuesta resultante de núcleos y conectores incluye la prestación de los servicios ecosistémicos que sustentan transversalmente su funcionalidad, en donde pese a su condición de mayor intervención, cumplen también roles específicos en la naturaleza. Desde este enfoque, el SVU propuesto presenta varios "ecosistemas" naturales y antrópicos en sus núcleos en distinto grado de conservación, asociados a funciones específicas y a grupos de organismos de fauna y flora. Al tiempo, los conectores del SVU son claves en los procesos de conservación, cuya conexión estructural influye en el paisaje y distribuye los diferentes tipos de hábitats que permiten la movilidad de las especies. En esta escala, el SVU y los servicios ecosistémicos de tipo cultural adquieren mayor protagonismo, enfocando los elementos núcleo y conectores para otorgar la diversidad cultural de la ciudad y sus interacciones sociales, generar entornos saludables, desarrollar educación ambiental, fortalecer la pertenencia y la valoración del patrimonio natural de la ciudad, entre otros (Figura 9). 


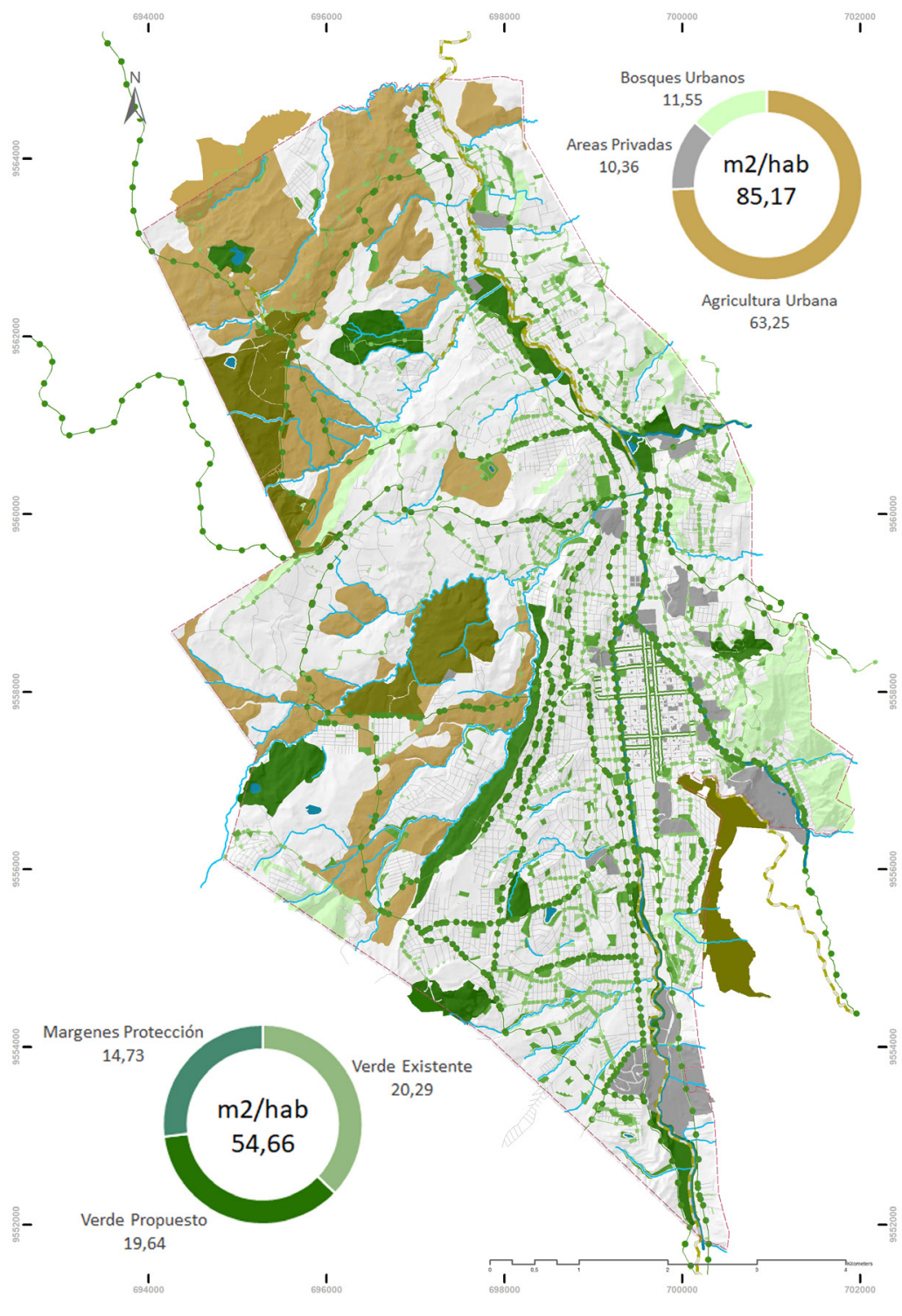

Figura 9: SVU. Modelo resultante

Fuente: Elaboración propia a partir de Municipio de Loja, UTPL y GIZ (2020a)

\section{Discusión de resultados}

Los resultados de la investigación aportan en el campo de IV desde el enfoque metodológico, que pone en valor los espacios naturales y seminaturales como estrategia principal para relacionar áreas urbanas y entornos rurales mediante una base procedimental cuya resultante propone sistemas verdes urbanos estructuradores de ciudades en contextos nacionales e internacionales. En la conceptualización del proceso metodológico es importante identificar que se analiza el verde desde dos significaciones: una, entendiéndolo como un sistema articulado, no solo como piezas de la ciudad, en donde se estudian relaciones, funciones y servicios que se complementan y dan sinergia al mismo; y dos, trascender una mirada meramente urbana por una territorial en donde no solo es importante el asentamiento sino la región que lo contiene y con la cual constituye un continuum biofísico natural.

Consecuentemente, la metodología desarrollada construye los pasos para estudiar la ciudad integral, identificar los elementos estructurantes, condicionantes y de oportunidad en su estado actual y armar con ellos un sistema estructurador urbano sobre el cual se proyecte la vida de la ciudad. Es precisamente el marco metodológico cumplido en la investigación el que aporta también como una base replicable de manera general en los contextos urbanos, en la diversidad y escala de ciudades, y específicamente en las urbes de Ecuador, que comparten, por un lado, características biofísicas, urbanas y ambientales, cercanas al caso de estudio, y por otro, las políticas públicas, estructura y funciones de gestión a través de sus gobiernos locales. 
En el balance de los resultados obtenidos de la aplicación metodológica se tienen a favor la visión multiescalar, tanto para el abordaje del estado actual como para la propuesta, que incluye el territorio con predominios naturales, las transiciones urbano rurales y el acercamiento a la ciudad como ambiente altamente modificado. La visión de escalas también destaca positivamente la inclusión de todos los elementos llamados núcleos y conectores de la red, sus condiciones, oportunidades sistémicas y gestión desde el campo interdisciplinar de la arquitectura, urbanismo y medio ambiente, entre otras.

Por otro lado, las limitantes de la metodología propuesta tienen que ver con las fuentes de información, que no son actualizadas o son inexistentes, debiendo recurrir adicionalmente a levantamientos de campo que traen mayores demandas de tiempo. Es precisamente el diagnóstico donde las primeras limitaciones de datos complican y alargan el proceso. La condición señalada determina que la metodología debe estar sistematizada con información geográfica desde las situaciones de partida y propuesta que llevan a dinamizarla en la planificación de la ciudad, desde sus planes como instrumentos técnicos y luego en la gestión implementación y seguimiento del SVU.

Puntualizando la discusión al caso de estudio, la propuesta presenta los cambios positivos con el SVU en la ciudad de Loja, que alcanzaría 875 hectáreas con un incremento equivalente al $89,9 \%$ de superficie total. Por lo tanto, el índice verde urbano llega a 54,66 m2/hab con las incorporaciones de núcleos y conectores en especial, los parques urbanos accesibles y equitativos en toda el área urbana y el gran núcleo de agricultura urbana. Además de los índices señalados, se destaca la conexión espacia y funcional del sistema propuesto, que lo ha posesionado como un soporte para la planeación de la ciudad de Loja a través de los instrumentos de planificación: Plan de Desarrollo y Ordenamiento Territorial (PDOT) en la escala cantonal y Plan de Uso y Gestión del Suelo (PUGS) en la escala urbana, en los cuales ya ha sido incluido. Asimismo, la proyección del SVU en la red de áreas protegidas de la hoya de Loja como parte estructurante en el sistema natural macro.

Para concluir, la estructura del sistema verde urbano como soporte de desarrollo se encamina certeramente a las ciudades hacia la sostenibilidad que equilibra sus componentes socio-económicos y ambientales, y se articula en la planificación urbana para construir sobre ella los lineamientos normativos, tratamientos urbanísticos que den paso a las actuaciones para implementarlo mediante programas y proyectos en donde será trascendental la participación activa de los ciudadanos para su permanencia. Para terminar, los resultados señalan que es posible con ellos abrir nuevos caminos para la investigación que determinen avanzar en los pasos para la implementación, estableciendo condiciones de diseño de los elementos del sistema en relación a los servicios ecosistémicos y su adaptación a cambio climático, e ir avanzando con la implementación y sistematización para ser replicados en otras ciudades.

\section{Recomendaciones}

Es de importancia indicar que esta investigación ha supuesto una aportación en el conocimiento de cómo el análisis y estructuración del verde urbano desde una visión de "sistema o red", puede contribuir de forma trascendental a planificar las urbes desde lo natural, evidenciando este enfoque como una alternativa para lograr ciudades sostenibles y resilientes conectadas con sus entornos rurales. Además, es pertinente declarar que este trabajo se establece en un marco que puede y debe dar continuidad a nuevas investigaciones enfocadas al desarrollo específico de lineamientos y proyectos de los denominados núcleos y conectores, a la investigación de biodiversidad urbana frente a especies invasoras, a la gestión de estos sistemas dentro de la planificación y a la accesibilidad y calidad de los espacios naturales, seminaturales y artificiales que forman parte de estos sistemas, más aún cuando son temas que han tomado mayor relevancia en el contexto de la planificación de los asentamientos ante nuevas emergencias.

\section{Agradecimientos}

El presente trabajo se deriva del proyecto de investigación de la Universidad Técnica Particular de Loja, con financiamiento externo de la Cooperación Alemana GIZ Ecuador, bajo su programa Ciudades Intermedias Sostenibles, en alianza con el Gobierno Autónomo Descentralizado del Cantón Loja.

Cómo citar este artículo/How to cite this article: Segarra-Morales, G., Torres-Gutiérrez, M. y González-Roldán, C. (2021). Sistema Verde Urbano de Loja, como base estructurante de la ciudad. Estoa. Revista de la Facultad de Arquitectura y Urbanismo de la Universidad de Cuenca, 10(20), 51-64. doi: 10.18537/est.v010.n020.a05 


\section{Referencias bibliográficas}

Alcaldía de Medellín. (26 de mayo de 2021). Descripciones de proyectos Secretaría de Infraestructura. https://www. medellin.gov.co/irj/portal/medellin? NavigationTarget=c ontenido/5744-Descripciones-de-proyectos-Secretariade-Infraestructura

Allen, J. y Balfour, R. (2014). Natural solutions for tackling health inequalities. UCL Institute of Health Equity https://www.instituteofhealthequity.org/resourcesreports/naturalsolutions-to-tackling-health-inequalities/ naturalsolutions-to-tackling-health-inequalities.pdf

Benedict, M. y McMahon, E. (2006). Green Infrastructure: Linking Landscapes and Communities. Island Press.

Borja, J. (2012). Espacio público y derecho a la ciudad. En Debats en Treball Social i Política Social. Universitat de Girona. https://debatstreballsocial.files.wordpress. com/2013/03/espacio_publico_derecho_ciudad_ jordiborja.pdf

Centro de Estudios Ambientales. (2016). La Infraestructura Verde Urbana de Vitoria-Gasteiz. Barrio a Barrio. CEA. Ayuntamiento de Vitoria-Gasteiz. https://www.vitoriagasteiz.org/docs/wb021/contenidosEstaticos/adjuntos/ en/47/38/64738.pdf

CINFA y Herbario Loja. (2006). Estado de conservación de áreas protegidas y bosques protectores de Loja y Zamora Chinchipe y perspectivas de intervención. Universidad Nacional de Loja. https://www.portalces.org/sites/ default/files/informeareaslojazamora.pdf

Constitución de la República del Ecuador [Const]. Art. 23, 31, 71. 20 de octubre de 2008 (Ecuador).

Davies, C., MacFarlane, R., McGloin, C. y Roe, M. (2015). Green infrastructure planning guide. Journal of Arboriculture, (30), 269-275.

De Vries, S. (2010). Nearby nature and human health looking at mechanisms and their implications. En C. Ward, P. Aspinall y S. Bell (Eds), Innovative Approaches to Researching Landscape and Health. Open Space: People Space 2. Routledge.

European Environment Agency - EEA. (2011). Green infrastructure and territorial cohesion. The concept of green infrastructure and its integration into policies using monitoring systems. EEA.

Fadigas, L. (2009). La estructura verde en el proceso de planificación urbana. Ciudades, (12), 33-47.

Hábitat III. (2017). Nueva Agenda Urbana. Naciones Unidas. https://uploads. habitat3.org/hb3/NUA-Spanish pdf

Hansen, R. y Pauleit, S. (2014). From Multifunctionality to Multiple Ecosystem Services? A Conceptual Framework for Multifunctionality. Green Infrastructure Planning for Urban Areas. AMBIO, (43), 516-529. https://doi org/10.1007/s13280-014-0510-2
Hartig T., Mitchell, R., De Vries, S. y Frumkin, H. (2014). Nature and Health. Annual Review of Public Health, 35, 207-228. https://doi.org/10.1146/annurevpublhealth-032013-182443

Hu, T., Chang, J. y Syrbe, R. (2020). Green Infrastructure Planning in Germany and China. A comparative approach to green space policy and planning structure. Inclusive Urbanism: Advances in research, education and practice, 6, 99-126. https://doi.org/10.7480/rius.6.96

INEC (2010). Censo Nacional de Población y Vivienda Gobierno de la República del Ecuador. https://www. ecuadorencifras.gob.ec/base-de-datos-censo-depoblacion-y-vivienda-2010-a-nivel-de-manzana/

Landscape Institute. (2009). Green infrastructure: connected and multifunctional landscapes. Landscape Institute Position Statement.

Matthews, T., Lo, A. y Byrne, J. (2015). Reconceptualizing green infrastructure for climate change adaptation: Barriers to adoption and drivers for uptake by spatial planners. Landscape and Urban Planning, 138, 155-163. https://doi.org/10.1016/j.landurbplan.2015.02.010

Municipio de Loja, UTPL y GIZ. (2020a). Laboratorio Urbano de Loja 2019. Integrar la naturaleza. Universidad Técnica Particular de Loja.

Municipio de Loja, UTPL y GIZ. (2020b). Plan del Sistema Verde Urbano de Loja. Universidad Técnica Particular de Loja.

Naciones Unidas. (2021). Objetivo 11: Lograr que las ciudades sean más inclusivas, seguras, resilientes y sostenibles. Objetivos de Desarrollo Sostenible. ONU. https://www.un.org/sustainabledevelopment/es/cities/

Sahagún, F., Aceves, J., Sánchez, E. y Plazola, L. (2020) Valoración de los servicios ecosistémicos en áreas verdes. El caso del Parque Metropolitano de Guadalajara, México. Acta universitaria, 30, e2635. https://doi. org/10.15174/au.2020.2635

Silva, C., Viegas, I., Panagopoulos, T. y Bell, S. (2018). Environmental Justice in Accessibility to Green Infrastructure in Two European Cities. Land, 7(4), 134. https://doi.org/10.3390/land7040134

Valdés, P. y Foulkes, M. (2016). La infraestructura verde y su papel en el desarrollo regional. Aplicación de los ejes recreativos y culturales de Resistencia y área metropolitana. Cuaderno Urbano. Espacio, cultura, sociedad, 20(20), 45-70.

Vásquez, A. (2016). Infraestructura verde, servicios ecosistémicos y sus aportes para enfrentar el cambio climático en ciudades: el caso del corredor ribereño del río Mapocho en Santiago de Chile. Revista de Geografía Norte Grande, 63, 63-86. http://dx.doi.org/10.4067/ S0718-34022016000100005 